\title{
A husband was said to have killed his wife and two children to re-marry another female met through social media: a glimpse in to criminal psychology
}

\begin{abstract}
Criminals cannot be judged with their appearance. As Judicial Medical Officers (JMOs) the authors frequently deal with criminally responsible individuals. The field of medicine is quite competent in giving evidence either for conviction or exoneration in most criminal trials. The law of the country is quite strong to punish the culprit. Yet, the important issue in this aspect is whether it is adequate to punish the criminals according to the law of the country or should there be anything further to be implemented as a dire requirement to address the tendency of being criminals with the view of reducing the number of criminal acts and also to have a mechanism to rehabilitate the already criminalized mindsets? A case report covering the criminal psychological aspects we want to discuss is as follows. A young father was said to have killed his two children along with his wife in a single occasion. Upon killing, he had set fire to the room to mimic accidental house burns. There is no doubt that with thorough medico-legal investigation the culprit would be punished in due time. The authors believe that not only the speculated punishments for the culprit but also the underlying criminal mind set for committing such acts should be thoroughly investigated by the academics including criminologists. These criminals are actually the best available resources in order to study the mindset or the criminal tendencies towards committing organized offences. Forensic psychology and psychiatry are ever evolving subjects as the modern world is literally changing with the influence of many new social theories and technologies. Most of the time criminals tend to justify the acts they performed according to their insight. So it is obvious that it is a dire requirement to study about such characters in our country by all related researches to help the society in two ways: to prevent further occurrences by the younger generation and to streamline the mindsets of the already criminalized personals.
\end{abstract}

Keywords: underlying causes for criminality, (identification of) criminal minds, forensic psychiatry, triple murder
Volume 6 Issue 4 - 2018

\author{
Ariyarathna HTDW, Hulathduwa SR \\ Department of Forensic Medicine, University of Sri \\ Jayewardenepura, Sri Lanka
}

\begin{abstract}
Correspondence: Ariyarathna HTDW, Senior Lecturer, Department of Forensic Medicine, Faculty of Medical Sciences, University of Sri Jayewardenepura, Nugegoda, Sri Lanka, Tel+94 II 2802030, Email weerawickramers@hotmail.com, ariyaratna@sjp.ac.Ik
\end{abstract}

Received: July 30, 2018| Published: August 13, 2018

\section{Introduction}

Killing of the wife and the two children in order to acquire a "better married life" with another female is not justifiable at any cost by a sensible person as there are many other non-criminal alternatives to achieve the said desired relationship. One would think that it is all right to kill anybody to achieve an easy and permanent way out of the existing family as he is not satisfied with the existing circumstances. Another person with the same circumstances would follow noncriminal path to make his life comfortable. ${ }^{1,2}$ This different thinking pattern should be investigated into. The tendency in committing criminal events is an existing phenomenon ever since the human civilization. Understanding the underlying causes for criminal minds is not behind any of the first class inventions of the present world. The already formulated theories along with the new perspectives, the criminal minds should be investigated into, more extensively than ever before in order to achieve a future generation with healthier minds. In addition to addressing the mindset of the younger generation, authors opine that it is essential to re-mold the mind setup of those who had been labelled as criminals already. ${ }^{3}$

\section{Case report}

The young husband in this case scenario had been a very clever man with good school performance in a leading school of the country.
The family was economically sound and no physical hardships were faced by that boy during his upbringing.

Later, he became employed in a reputed company as a well-paid executive with many incentives. He was keen on further studies along with his current employment as well. He later had married a teacher in a well reputed school of the country and became the father of two children. His mother was a retired teacher and his late father was a retired government executive who passed away some time prior to the incident. It was revealed that the suspect had treated his wife with much love and affection without any arguments or quarrels during their relatively short married life. A luxurious and cozy life-style had been offered to his wife and two children.

However in a particular morning it appeared as if the room where his wife and two children were sleeping had been burnt down resulting in the death of all three of them. The police had started the investigations assuming that it was an accidental burn and no suspicion was raised at all by any party including the investigating police, relatives, neighbours or the general public.

The scene investigation and the post mortem examinations were performed with the proper legal authority from the honourable magistrate. The post mortem examination of the mother revealed that she had been killed by applying pressure over the neck and it 
was evident that setting fire on the body was subsequent to the death. Immediately the investigating police officer was called and made aware of the nature of the death and advised to take the suspects in to custody after informing the magistrate of the altered circumstances. Initially, the police were reluctant to accept the post mortem findings as the behavior and the family background was not adequately supportive to convince that they are dealing with a secret triplemurder. Meanwhile the other two post mortems were also performed confirming the homicidal circumstances. Subsequently, the police had taken the husband into custody and interrogation had been started though he did not voluntarily confessed of committing the triple homicide.

A quick search of the telephone of the husband revealed many clues. The extra marital affair that he had been having with a relatively young girl was strongly and evidentially suspected of, as the immediate trigger in committing these secret triple homicides. Later it was revealed that he wanted to kill his wife and two children and then to mimic it as an accidental burn and then to marry that young girl as an innocent widower. A luxurious house also had been purchased for their new married life closer to girl's home town. He also had gone into the extent of hiring fake parents to be present in front of that young girl. He had resigned from the financially rewarding and lucrative job he was holding in a reputed private company two weeks prior to the homicide, perhaps to buy time to plan his plot in a flawless manner. All these events well established the premeditated and planned nature of his secret triple homicide.

\section{Discussion}

It is impossible to eradicate criminals form a given society. Yet, it is certainly possible to prevent certain vulnerable characters in becoming criminals. This is the most important aspect that authors want to highlight by elaborating this case. It is not easy to identify the underlying causes, triggers and characters as to why only certain individuals exhibit a criminal behavior under given circumstance. There are many theoretical perspectives to understand and explain the criminal behavior. ${ }^{4}$ There is little or no value in having numerous theories or bodies of knowledge surrounding the criminal behavior unless they are to be effectively utilized for primary or secondary prevention of crime. Micro and macro level analysis of the criminal mindset is extremely important in this respect. Not only for that, but also to rehabilitate the existing mindsets of those who are already identified or labelled as criminals, this approach is prudent.

\section{Conclusion}

Criminal mind set should be investigated in order to prevent further criminal acts in the future and this knowledge should be employed to bring up psychologically healthy children in our country, starting from the primary school up to university level. It is not adequate to address the criminals only for punishments. They are real text book like resources to study the changing dynamics of forensic psychiatry and criminal psychology. Their behavior and thinking patterns could be studied in depth primarily to change their own criminal mind set and secondarily to assist the general rehabilitation and education process of the country.

\section{Acknowledgements}

None.

\section{Conflict of interest}

The author declares no conflict of interest.

\section{References}

1. Van Gelder J. Affect and cognition in criminal decision making. London: Routledge; 2014.

2. Rational choice theory (criminology). (2018).

3. Clara Moskowitz. Criminal minds are different from yours, brain scans reveal. Live Science. 2018.

4. Hall E. Theoretical perspectives to understand and explain the criminal behavior criminology and Justice. 2018. 